\title{
MESTRES EM CIÊNCIAS CONTÁBEIS: UMA ANÁLISE SOB A ÓTICA DA TEORIA DO CAPITAL HUMANO ${ }^{1}$
}

\section{MASTERS IN ACCOUNTING: AN ANALYSIS ACCORDING TO HUMAN CAPITAL THEORY}

\section{MASTERES EN CIENCIAS CONTABLES: UN ANÁLISIS BAJO LA ÓPTICA DE LA TEORÍA DEL CAPITAL HUMANO}

\author{
ORLEANS SILVA MARTINS \\ Professor da Universidade Estadual da Paraíba - UEPB \\ Mestre em Ciências Contábeis pela UnB/UFPB/UFRN \\ orleansmartins@yahoo.com.br
}

PAULO AGUIAR DO MONTE

Prof. Adjunto II Departamento de Economia - UFPB

Doutor em Economia - PIMES/UFPE

Professor do Programa de Pós-Graduação em Economia e do Programa Multiinstitucional e Inter-Regional de Pós Graduação em CiênciasContábeis da UnB/UFPB e UFRN.

pauloaguiardomonte@gmail.com

\section{RESUMO}

O objetivo deste estudo é traçar o perfil do mestre egresso do Programa Multi-institucional e Inter-regional de Pós-Graduação em Ciências Contábeis da UnB/UFPB/UFPE/ UFRN, investigando as influências dessa titulação em seu perfil. O referencial teórico do estudo fundamenta-se na Teoria do Capital Humano. A metodologia adotada caracteriza-se como descritiva, apoiada no método indutivo, utilizando as técnicas da pesquisa bibliográfica, documental e questionário. Aplicou-se um questionário a 96 egressos deste programa, entre os dias $1^{\circ}$ de julho e 31 de agosto de 2008, representando $70,07 \%$ da população investigada. Para efetuar a análise descritiva e estatística dos dados, foram utilizados os softwares Excel e SPSS. Em seus resultados, verificou-se que, em sua maioria, os mes- 
tres são homens (65,63\%); atualmente moram em um dos estados/cidade que integram o Programa (80,21\%); possuem aproximadamente 39 anos; e são casados (64,58\%). Antes do mestrado, $62,50 \%$ deles ministravam aulas em alguma IES e, após sua conclusão, este número subiu para $79,17 \%$. Isto evidencia a influência do título de mestre na reorientação profissional dos mestres, ao passo que parcela significativa desses profissionais passou a atuar na área acadêmica, o que ratifica os preceitos da Teoria do Capital Humano, uma vez que pode ser observada a influência da referida escolaridade na empregabilidade e na renda desses profissionais.

Palavras-chave: Mestrado. Ciências Contábeis. Teoria do Capital Humano.

\section{ABSTRACT}

The objective of this study is to trace the Master's degree profile of leaving the Multiinstitucional and Inter-regional Program for the Master's degree in Accounting Sciences of the UnB/UFPB/UFPE/UFRN universities, investigating the influences of that diploma on his profile. The theoretical framework of the study is based on the Human Capital Theory. The methodology is characterized as exploratory-descriptive leaning toward the inductive method, using the techniques of bibliographical and documental research, including questionnaires. A questionnaire was given to 96 students leaving this program, between July 01 and August 31, 2008, representing $70,07 \%$ of the investigated population. To do the descriptive and statistical analysis of the data, the softwares Excel and SPSS were used. From the results, it was found that, for the most part, the Masters are men $(65,63 \%)$, they live in one of the states/city that make up the Program (80,21\%), are approximately 39 years old and are married (64,58\%). Before the Master's degree, $62,50 \%$ of them gave classes in some IES and, after his conclusion, this number increased for $79,17 \%$. This shows the influence of Master's degree in a new professional orientation of this group, in that a significant number of those professionals then started to act in the academic arena, which confirms the precepts of the Human Capital Theory, because we can observe the influence of that education on the employability and on the income of these professionals.

Keywords: Master's Degree. Accounting Sciences. Human Capital Theory.

\section{RESUMEN}

El objetivo de este estudio es trazar el perfil del master egreso del Programa Multiinstitucional e Inter-regional de Pos-Graduación en Ciencias Contables de la UnB/UFPB/ UFPE/UFRN, investigando las influencias de esa titulación en su perfil. El referencial teórico del estudio está fundamentado en la Teoría del Capital Humano. La metodología 
adoptada se caracteriza como descriptiva, apoyada en el método inductivo, utilizando las técnicas de la pesquisa bibliográfica, documental y de cuestionario. Fue aplicado un cuestionario a 96 egresos de este programa, entre los días $1^{\circ}$ de julio y 31 de agosto de 2008, representando el $70,07 \%$ de la población investigada. Para efectuar el análisis descriptivo y estadístico de los datos, fueron utilizados los softwares Excel y SPSS. En sus resultados, se verificó que, en su mayoría, los masteres son hombres $(65,63 \%)$; actualmente viven en uno de los estados/ciudad que integran el Programa (80,21\%); tienen aproximadamente 39 años; y están casados (64,58\%). Antes del master, el $62,50 \%$ de ellos impartían clases en alguna IES y, después de su conclusión, este número subió hasta el $79,17 \%$. Esto evidencia la influencia del título de master en la reorientación profesional de los masteres, al paso que una parte significativa de esos profesionales pasó a actuar en el área académica, lo que ratifica los preceptos de la Teoría del Capital Humano, una vez que puede ser observada la influencia de la referida escolaridad en la facilidad de conseguir empleo y en la renta de esos profesionales.

Palabras clave: Master. Ciencias Contables. Teoría del Capital Humano.

\section{CONTEXTUALIZAÇÃO}

A Teoria do Capital Humano fundamenta-se no conceito de que a aquisição de mais conhecimentos e habilidades aumenta o valor do capital humano das pessoas, aumentando sua empregabilidade, produtividade e rendimento potencial. Por sua vez, com maior conhecimento, os agentes buscam no mercado de trabalho maiores rendimentos futuros. Com isso, o nível de escolaridade passa a ser o principal fator na determinação do perfil de renda de um trabalhador ao longo de sua vida, o que faz com que o treinamento, a reciclagem e a especialização passem a ser termos comuns no dia-a-dia das pessoas.

A educação em Ciências Contábeis é um tema ainda pouco discutido e estudado, principalmente no Brasil. Ao se realizar uma busca por trabalhos que tratem do tema em termos mundiais, são encontrados poucos estudos e, principalmente, originários de países como Estados Unidos e Inglaterra. No Brasil, estes estudos são ainda mais raros, principalmente, quando se trata da pós-graduação stricto sensu em Ciências Contábeis. Não se verificou a existência de pesquisas que abordassem os mestres em Ciências Contábeis egressos de um programa de pós-graduação stricto sensu no país.

O primeiro curso de mestrado em Ciências Contábeis no Brasil foi criado no ano de 1970, pela então Faculdade de Ciências Econômicas e Administrativas da Universidade de São Paulo (FEA/USP). No contexto da pós-graduação brasileira, o Programa Multi-institucional e Inter-regional de Pós-Graduação em Ciências Contábeis da UnB/UFPB/UFPE/ UFRN destacou-se pelo pioneirismo da multi-institucionalidade na área e, por ser o primeiro 
a oferecer o curso de mestrado em Contabilidade nas regiões Nordeste e Centro-Oeste do país. Entretanto, no ano de 2007, a UFPE desvinculou-se do Programa Multi-institucional, uma vez que teve seu próprio programa de mestrado aprovado pela Capes. Hoje, o Brasil possui 18 programas de pós-graduação stricto sensu em Ciências Contábeis, que possuem o curso de mestrado em nível acadêmico ou profissional, reconhecidos pela Coordenação de Aperfeiçoamento de Pessoal de Nível Superior (CAPES).

Dessa forma, o estudo deste tema justifica-se pela escassez de estudos relacionados e pela relevância que têm as informações que dele provêm, de suma importância para servir como fonte de consulta a futuros aspirantes ao referido título, às instituições de fomento à pesquisa, às IFES componentes do Programa, entre outros atores, além de possibilitar a compreensão do papel e das contribuições do Programa para o desenvolvimento dos indivíduos que dele fazem parte, e para a sociedade.

Sendo assim, o objetivo deste estudo é traçar o perfil do mestre egresso do Programa Multi-institucional e Inter-regional de Pós-Graduação em Ciências Contábeis da UnB/UFPB/ UFPE/UFRN, investigando as influências dessa titulação em seu perfil. Para tanto, busca-se responder ao seguinte problema de pesquisa: qual o perfil do mestre titulado pelo Programa Multi-institucional e Inter-regional de Pós-Graduação em Ciências Contábeis da UnB/UFPB/UFPE/UFRN e qual a influência dessa titulação em seu perfil?

\section{A TEORIA DO CAPITAL HUMANO}

Em sua essência, a Teoria do Capital Humano fundamenta-se no conceito de que a aquisição de mais conhecimentos e habilidades aumenta o valor do capital humano das pessoas, aumentando sua empregabilidade, produtividade e rendimento potencial (BECKER, 1962; BLAUG, 1976). Mincer (1974), ao tentar medir o capital humano, supôs que esta variável seria proporcional ao número de anos de instrução ou treinamento que um indivíduo possuísse. Nesse sentido, Schultz (1961) afirmou que, investindo em si mesmas, as pessoas poderiam aumentar a gama de escolhas disponíveis a elas. Esta seria, então, uma forma livre de os homens aumentarem seu bem-estar.

A teoria busca explicar, nos marcos das teorias neoclássicas convencionais, a razão da existência de diferenciações salariais. A ideia básica é que, da mesma forma como é possível investir em ativos físicos a fim de auferir rendas maiores no futuro, como, por exemplo, em ações de uma empresa, é razoável que um indivíduo invista em sua formação, pela educação ou por meio de cursos de qualificação, para obter rendimentos futuros maiores (BECKER, 1962; BLAUG, 1965; SCHULTZ, 1973). Na perspectiva de Blaug (1985), a Teoria do Capital Humano é resultado de um programa de pesquisa, uma vez que não é possível associá-la a uma única teoria. Consequentemente, o núcleo desse programa consiste na ideia de que o indivíduo investe em si mesmo de formas diversas, não apenas 
buscando desfrutar o presente, mas procurando rendimentos futuros, pecuniários ou não.

Frigotto (2003) observa que a idéia-chave dessa teoria é a de que um acréscimo marginal de instrução, treinamento e educação correspondem a um acréscimo marginal de capacidade de produção do indivíduo. Assim, o termo capital humano seria uma ideia de "quantidade" de educação e qualificação tomada como indicativo de um determinado volume de conhecimentos, habilidades e atitudes adquiridas, que funciona como potencializador da capacidade de trabalho e produção. Nesse sentido, seus adeptos pregam a ampliação das habilidades dos indivíduos e da qualidade de seu trabalho como uma modalidade de investimento. Segundo Lima (1980, p. 226), a lógica da teoria é a seguinte:
a) as pessoas se educam;
b) a educação tem como principal efeito mudar suas "habilidades" e conhecimentos;
c) quanto mais uma pessoa estuda, maior é sua habilidade cognitiva e sua pro- dutividade;
d) maior produtividade permite que as pessoas recebam maiores rendas.

Ross, Westerfield e Jaffe (1995) atentam que investir em capital humano não é diferente de investir em máquinas de uma empresa, no que diz respeito à análise do retorno do investimento. Se indivíduos com maior qualificação pessoal e profissional tendem a perceber salários mais elevados, então isso quer dizer que, ao investir em capital humano, o indivíduo busca assegurar melhores condições salariais futuras, ou seja, ele deseja o retorno do investimento. Nesse sentido, Soares (2007) assevera que a relação entre ensino e trabalho se modificou, tornando-se cada vez mais imperativa a necessidade de formar um novo trabalhador que atenda a esta nova demanda, o qual possua os requisitos necessários para se empregar e manter sua empregabilidade.

\subsection{Retornos Sobre a Educação}

O capital humano ocupa importante papel no crescimento econômico de um país, uma vez que ele influencia diretamente a criação de tecnologia, no sentido de que pessoas mais capacitadas realizam mais trabalho, ou trabalho de melhor qualidade, em um mesmo período de tempo, elevando sua produtividade (FERREIRA, 2008). Nessa ótica, o capital humano é um elemento indispensável para o desenvolvimento dos indivíduos e de suas nações. Sheehan (1975) ratifica esta observação ao afirmar que os cálculos da taxa de retorno privada para a educação têm resultados altos, em torno de $10 \%$ ou mais, em quase todos os casos.

Consolidando esta observação, Psacharapoulos e Patrinos (2002) investigaram os retornos do investimento em educação em 98 países, concluindo que a taxa média de retorno de mais um ano de estudo na vida de um indivíduo é de $10 \%$ ao ano. Ainda, conforme os autores, as maiores taxas de retorno são encontradas em países latino-americanos, 
nos países da região do Caribe e da África Subsaariana e as menores são observadas em países da Organização para a Cooperação Econômica e Desenvolvimento (OECD). Neri (2007) ainda observa que o Brasil é um dos países latino-americanos que possui o maior índice de diferença salarial entre quem frequentou um curso superior e os analfabetos, revelando que o mercado paga mais a quem tem mais estudo (GASTALDON, 2007).

Estudos recentes realizados fora do Brasil reforçam os achados da Teoria do Capital Humano quanto à estreita relação entre educação, trabalho e desenvolvimento econômico, tendo o capital humano como base para o desenvolvimento individual e coletivo (HUNTER; BROWN, 2000; RIDDELL, 2004; BROWN; HUNTER, 2004; LOENING, 2005; ROBEYNS, 2006; ZULA; CHERMACK, 2007; STURMAN; WALSH; CHERAMIE, 2008). No Brasil, estudos como os de Barros, Mendonça e Henriques (2002), Moretto (2002), Curi (2006), Néri (2007) e Ferreira (2008) evidenciam a estreita relação existente entre educação e mercado de trabalho, apontando que, quanto mais alta é a escolaridade, maiores as chances de se conseguir ou manter um bom emprego, com melhores salários.

Em se tratando da educação na área das Ciências Contábeis, são encontrados os estudos de Néri (2007) e Cunha (2007). Néri (2007) observou que, em termos salariais, os indivíduos que possuem mestrado e doutorado em Ciências Contábeis ou Econômicas possuem uma das melhores remunerações entre as profissões analisadas, com salários até $1.503 \%$ maiores do que os daqueles que nunca frequentaram uma escola. Em relação à probabilidade de se conseguir um emprego, eles apresentaram uma probabilidade oito vezes maior do que os analfabetos ( $21^{\circ}$ lugar no ranking). Quanto à remuneração, os pósgraduados em Ciências Contábeis ou Econômicas demonstraram uma média mensal de $\mathrm{R} \$ 7.085,24$ (4 ${ }^{\mathrm{a}}$ maior entre as analisadas), enquanto os graduados na área apresentaram uma média de $\mathrm{R} \$ 3.099,10$ (39a maior entre as analisadas). Neste sentido, Cunha (2007) observa que os estudos realizados no Brasil apresentam resultados bastante consistentes e não diferem muito daqueles obtidos em outros países. Assim, pode-se afirmar com segurança que pessoas com níveis mais altos de educação têm maiores probabilidades de receberem salários mais elevados. Esses resultados, além de consistentes, são recorrentes e mostram que, em média, um ano adicional de escolaridade aumenta a renda em mais de $10 \%$. Este retorno está entre os mais altos do mundo.

\section{PROCEDIMENTOS METODOLÓGICOS}

\subsection{Caracterização do Estudo}

Quanto à sua classificação, é descritiva, uma vez que "tem como principal objetivo a descrição das características de determinada população ou fenômeno, estabelecendo relações entre as variáveis" (SILVA, 2003, p. 65). Sendo assim, a pesquisa busca descrever as características dos alunos egressos do programa ora estudado. Os resultados a serem 
obtidos por meio da pesquisa poderão contribuir no sentido de identificar relações existentes entre as variáveis estudadas desta população (BEUREN, 2006).

\subsection{Métodos e Procedimentos}

A pesquisa se apoia no método indutivo que, segundo Richardson (2008), parte das premissas dos fatos observados para se chegar a uma conclusão que contenha informações sobre fatos ou situações não-observadas, perfazendo o caminho do particular para o geral.

Quanto aos procedimentos, foi utilizada a pesquisa bibliográfica, constituindo parte da pesquisa descritiva, por meio da qual foi possível investigar o estado da arte da Teoria do Capital Humano e da pós-graduação em Ciências Contábeis no Brasil, a pesquisa documental, por intermédio da qual foi possível realizar um levantamento de documentos do Programa e dos currículos Lattes publicados na Plataforma Lattes do Conselho Nacional de Desenvolvimento Científico e Tecnológico (CNPq), buscando obter informações sobre o Programa e seus egressos e aplicados questionários.

\subsection{População e Amostra}

A população objeto de estudo são todos os egressos titulados pelo referido programa até o dia 31 de dezembro de 2007, totalizando 137 mestres. Tendo em vista o pequeno número de elementos desta população, buscou-se localizar um número de egressos que garantisse estatisticamente a generalização das características observadas à população total. Sendo assim, baseando-se em Gil (1999), foi estabelecido um nível de confiança de 95\% ( $\sigma$ $=1,96)$, a percentagem de respostas esperadas $(p=0,70)$, a percentagem complementar $(q=0,30)$ e o erro máximo permitido para a amostra $(e=0,05)$, como se segue:

$\mathrm{n}=\frac{\sigma^{2} \cdot p \cdot q \cdot \mathrm{N}}{\mathrm{e}^{2}(\mathrm{~N}-1)+\sigma^{2} \cdot \mathrm{p} \cdot \mathrm{q}} \rightarrow \mathrm{n}=\frac{1,96 \underline{2}^{2} \cdot 0,70 \cdot 0,30 \cdot 137}{0,05^{2}(137-1)+1,96^{2} \cdot 0,70 \cdot 0,30}$
$\mathrm{n}=\frac{110,522832}{1,146736} \rightarrow \mathrm{n}=96,38036305$

\subsection{Coleta e Análise dos Dados}

Os dados foram coletados a partir da aplicação de um questionário entre os meses de julho e agosto de 2008, a 96 egressos componentes da amostra, selecionados por meio de sorteio aleatório. Foi aplicado previamente um pré-teste com uma amostra-piloto de seis especialistas. Do total de questionários aplicados e respondidos, 92 foram via e-mail e 4 diretamente aos mestres. Para a análise e a interpretação dos resultados, os dados foram tabulados no software Excel e, posteriormente, extraídos para o pacote estatístico SPSS 16.0.1. 


\section{repec}

\section{ANÁLISE E DISCUSSÃO DOS RESULTADOS}

Dos 96 mestres que compuseram a amostra, aleatoriamente, 42 fizeram parte do núcleo Brasília e 54 do núcleo Nordeste. Segundo suas opiniões e percepções, pode-se traçar o perfil do mestre em Ciências Contábeis egresso deste programa.

\subsection{Perfil do Mestre em Ciências Contábeis}

Analisando-se o perfil do egresso do Programa, tendo em vista seu objetivo de qualificar corpo docente para as regiões Nordeste e Centro-Oeste, pode-se observar que, de forma geral, $80,21 \%$ desses egressos moram atualmente em um dos estados/cidade que compunham o Programa (Pernambuco, Paraíba, Rio Grande do Norte e Brasília). Quanto à taxa de migração destes egressos a outros estados, os mestres concludentes pelo núcleo Brasília apresentam maior tendência, ao passo que $25,58 \%$ deles migraram para outras localidades, enquanto os concludentes pelo núcleo Nordeste apresentaram uma taxa de migração de apenas $16,67 \%$.

Ao analisar o gênero dos egressos, nota-se que ainda há uma predominância dos homens (65,63\% contra 34,37\% de mulheres), como se observa no Gráfico 1.

\section{Gráfico 1 - Percentual de homens e mulheres da amostra pesquisada.}

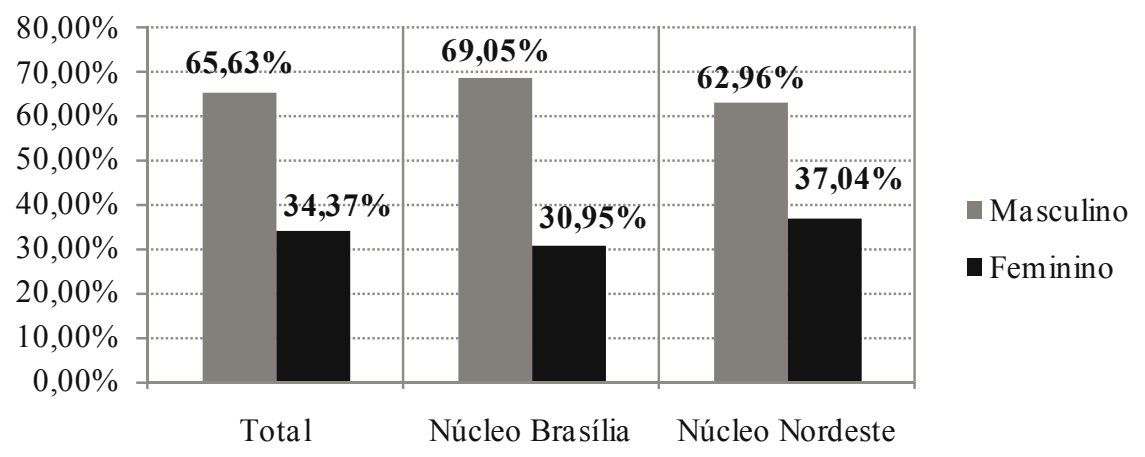

Fonte: Elaboração própria, com base nos dados coletados.

Segundo Velloso e Velho (2001), há uma tendência de aumento da proporção do sexo feminino na pós-graduação em vários países do mundo. No núcleo Brasília, essa relação é ainda mais desigual, tendo em vista que $69,05 \%$ do total de respondentes são compostos por homens (30,95\% são mulheres). Já no núcleo Nordeste, essa diferença é suavemente reduzida, uma vez que o sexo masculino representou $62,96 \%$ da amostra, contra $37,04 \%$ do sexo feminino. A média de idade apresentada pelos egressos dos dois núcleos foi de 38,76 anos. O egresso titulado como mestre em Ciências Contábeis com menor idade possuía 25 anos, ao passo que o de maior idade possuía 66 anos. Nos dois 
núcleos, os homens possuem uma média de idade superior à das mulheres. No núcleo Brasília, a média de idade dos homens é de 40,38 anos, enquanto a das mulheres é de 35,67 anos. Já no núcleo Nordeste, a média de idade dos homens é de 38,76 anos, enquanto a das mulheres é de 34,25 anos. Dessa forma, além de observar que, em geral, as mulheres conseguem sua titulação com uma idade menor do que a dos homens, nota-se que os mestres concludentes pelo núcleo Nordeste possuem uma média de idade inferior que os concludentes pelo núcleo Brasília.

Quanto ao estado civil dos mestres em Ciências Contábeis, pode-se observar que, tanto no núcleo Brasília quanto no núcleo Nordeste, a maioria é composta por casados. $O$ Gráfico 2 demonstra que, de uma forma geral, cerca de $64,58 \%$ dos egressos são casados, $19,79 \%$ são solteiros e 15,63\% são separados. No núcleo Brasília, pode-se notar uma pequena redução do percentual de casados e um suave aumento no número de solteiros. Já no núcleo Nordeste, os percentuais permaneceram bem próximos aos percentuais gerais.

\section{Gráfico 2 - Estado civil dos mestres em Ciências Contábeis.}

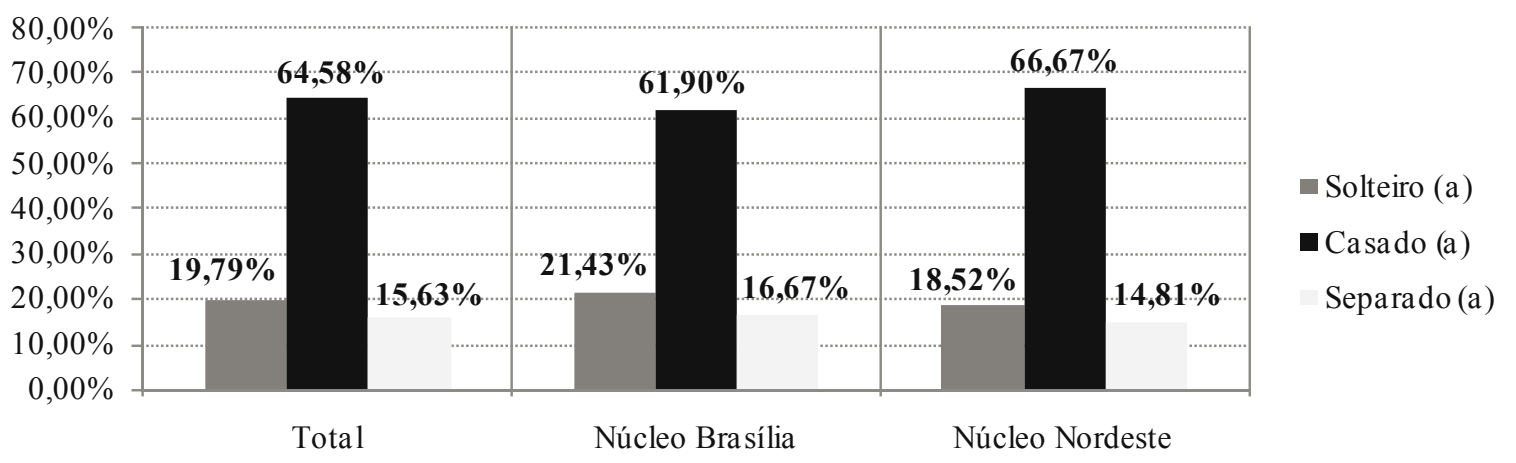

Fonte: Elaboração própria com base nos dados coletados.

\subsubsection{Trajetória acadêmica}

Os mestres em Ciências Contábeis titulados pelo Programa Multi-institucional terminaram sua graduação, em média, aos $25,63^{2}$ anos, com desvio padrão de 4,97 anos. Esta média é maior do que a apurada por Cunha (2007) com os doutores em Ciências Contábeis titulados pela FEA/USP, que apresentaram 24,40 anos, e maior do que a média apurada por Velloso (2002) em sua pesquisa com os mestres e doutores de várias áreas no Brasil, que girou entre 23 e 25 anos.

Em sua maioria, os mestres são procedentes da mesma graduação. Dos 96 respondentes, cerca de 93,75\% são graduados em Ciências Contábeis. No núcleo Nordeste, essa relação é ainda mais forte, tendo em vista que $96,30 \%$ dos egressos são graduados em Ciências Contábeis. No núcleo Brasília, esse percentual é um pouco menor (90,48\%), como se observa na Tabela 1. Quanto às graduações, $75,00 \%$ dos egressos possuem apenas a 
graduação em Ciências Contábeis; 5,21\% possuem apenas uma em Economia, Estatística ou Administração; 7,29\% possuem duas graduações, sendo a primeira em Ciências Contábeis e a segunda em cursos como Direito, Engenharia de Minas, Processamento de Dados ou Administração; 11,46\% possuem duas, sendo a primeira em cursos como Educação Física, Biblioteconomia, Engenharia Agronômica, Engenharia Civil, Teologia, Biologia, Tecnologia Superior em Cooperativismo ou Direito e a segunda em Ciências Contábeis; e $1,04 \%$ possuem duas graduações em cursos como Administração e Direito.

Tabela 1 - Formação acadêmica dos mestres em Ciências Contábeis.

\begin{tabular}{|c|c|c|c|c|c|c|}
\hline \multirow[t]{2}{*}{ Formação Acadêmica } & \multicolumn{2}{|c|}{ Total } & \multicolumn{2}{|c|}{ Núcleo Brasília } & \multicolumn{2}{|c|}{ Núcleo Nordeste } \\
\hline & $\mathbf{N}$ & $\%$ & $\mathbf{N}$ & $\%$ & $\mathbf{N}$ & $\%$ \\
\hline \multicolumn{7}{|l|}{\begin{tabular}{|l|} 
Possui graduação em \\
Ciências Contábeis
\end{tabular}} \\
\hline Sim & 90 & 93,75 & 38 & 90,48 & 52 & 96,30 \\
\hline Não & 6 & 6,25 & 4 & 9,52 & 2 & 3,70 \\
\hline \multicolumn{7}{|l|}{$\begin{array}{l}\text { Possui mais de uma } \\
\text { graduação }\end{array}$} \\
\hline Sim & 19 & 19,79 & 11 & 26,19 & 8 & 14,81 \\
\hline Não & 77 & 80,21 & 31 & 73,81 & 46 & 85,19 \\
\hline \multicolumn{7}{|l|}{ Possui especialização } \\
\hline Sim & 74 & 77,08 & 36 & 85,71 & 38 & 70,37 \\
\hline Não & 22 & 22,92 & 6 & 14,29 & 16 & 29,63 \\
\hline \multicolumn{7}{|l|}{$\begin{array}{l}\text { Especialização na área } \\
\text { das Ciências Contábeis* }\end{array}$} \\
\hline Sim & 62 & 83,78 & 29 & 80,56 & 33 & 86,84 \\
\hline Não & 12 & 16,22 & 7 & 19,44 & 5 & 13,16 \\
\hline \multicolumn{7}{|l|}{ Possui doutorado } \\
\hline Sim & 1 & 1,04 & 0 & 0,00 & 1 & 1,85 \\
\hline Em curso & 13 & 13,54 & 6 & 14,29 & 7 & 12,96 \\
\hline Não & 82 & 85,42 & 36 & 85,71 & 46 & 85,19 \\
\hline
\end{tabular}

${ }^{*}$ Apenas os mestres que possuem especialização (74).

Fonte: Elaboração própria, com base nos dados coletados.

Ainda na Tabela 1, pode-se observar que $77,08 \%$ dos egressos possuem pelo menos uma pós-graduação lato sensu ao nível de especialização. Essa constatação é mais expressiva nos egressos do núcleo Brasília, tendo em vista que nesse núcleo $85,71 \%$ dos egressos possuem ao menos uma especialização, enquanto no núcleo Nordeste este percentual foi de $70,37 \%$. De forma geral, $83,78 \%$ das especializações são na área de Contabilidade. Do total de respondentes que possui especialização, $29,73 \%$ possuem mais de uma. Daqueles que não possuíam especialização (22,92\%), 19,79\% ingressaram direto da graduação para o mestrado, sem intervalo de tempo, e outros 3,13\% ingressaram após 3 anos, em média. 
O prazo médio de conclusão da especialização apresentado pelos egressos foi de 15,68 meses, com um desvio padrão de 5,51 meses, o que denota grande alternância entre os períodos de conclusão dos cursos. Já o tempo transcorrido entre o fim da graduação e o início do mestrado foi de 86,08 meses (aproximadamente 7 anos e 2 meses), com desvio padrão de 6,31 anos, dispersão elevada demonstrando trajetórias diferenciadas. No núcleo Brasília, essa média é significativamente superior, chegando a 8 anos e 8 meses, enquanto no núcleo Nordeste foi de aproximadamente 6 anos, como pode ser observado na Tabela 2.

\section{Tabela 2 - Tempo médio transcorrido em cada uma das etapas da formação dos mestres (em meses).}

\begin{tabular}{|l|r|r|r|}
\hline Etapa da Formação & Total & Núcleo Brasília & Núcleo Nordeste \\
\hline Graduação & 58,11 & 59,98 & 56,67 \\
\hline Mínimo & 34 & 34 & 39 \\
\hline Máximo & 182 & 182 & 101 \\
\hline Desvio padrão & 17,31 & 23,42 & 10,37 \\
\hline Especialização & 15,68 & 15,25 & 16,08 \\
\hline Mínimo & 4 & 4 & 8 \\
\hline Máximo & 31 & 30 & 31 \\
\hline Desvio padrão & 5,51 & 5,64 & 5,42 \\
\hline Mestrado & 25,82 & 25,79 & 25,85 \\
\hline Mínimo & 17 & 18 & 17 \\
\hline Máximo & 35 & 35 & 33 \\
\hline Desvio padrão & 3,38 & 3,59 & 3,24 \\
\hline Doutorado (previstos) & 43,43 & 42,83 & 43,88 \\
\hline Mínimo & 34 & 36 & 34 \\
\hline Máximo & 54 & 54 & 54 \\
\hline Desvio padrão & 6,49 & 6,77 & 6,71 \\
\hline Entre a graduação e o mestrado & 86,08 & 103,69 & 72,39 \\
\hline Mínimo & 0 & 1 & 0 \\
\hline Máximo & 331 & 331 & 71,27 \\
\hline Desvio padrão & 75,77 & 78,57 & \\
\hline
\end{tabular}

Fonte: Elaboração própria, com base nos dados coletados.

Quando comparada ao estudo de Cunha (2007), percebe-se que a média geral de tempo transcorrido entre a graduação e o mestrado apresentada pelos egressos deste Programa é bem superior a dos doutores em Ciências Contábeis titulados pela FEA/USP, que é de 6 anos. No entanto, a média apresentada por aqueles doutores é a mesma apresentada pelos egressos que compõem o Núcleo Nordeste deste Programa. Quanto ao prazo médio de conclusão do mestrado apresentado pelos respondentes, verificou-se uma média de 2 anos e 2 meses, bem inferior à apresentada pelos doutores em Ciências Contábeis 
titulados pela FEA/USP, que apresentaram uma média de conclusão do mestrado de aproximadamente 3 anos e 9 meses (CUNHA, 2007). Essa diferença se relaciona em parte ao encurtamento do prazo máximo de realização dos cursos de mestrado, conforme disciplinado pela Coordenação de Aperfeiçoamento de Pessoal de Nível Superior (Capes).

Quanto ao doutorado, observou-se que $85,42 \%$ dos egressos ainda não possuem ou cursam um doutorado; $1,04 \%$ já concluíram o doutorado (apenas um egresso no programa de Contabilidade e Controladoria da FEA/USP); e outros 13,54\% estão o cursando durante a realização da pesquisa (13 mestres). Desse total de doutorandos, 78,57\% cursam o doutorado em Contabilidade, enquanto outros $21,43 \%$ cursam o doutorado em outras áreas, como pode ser observado na Tabela 3.

\section{Tabela 3 - Área do curso de doutorado dos mestres em Ciências Contábeis.}

\begin{tabular}{|l|c|c|c|}
\hline Curso & Instituição & Frequência & Percentual \\
\hline Contabilidade e Controladoria & USP & 7 & $50,00 \%$ \\
\hline Ciências Contábeis & UnB/UFPB/UFRN & 2 & $14,30 \%$ \\
\hline Contabilidade e Finanças & $\begin{array}{c}\text { Universidad de } \\
\text { Zaragoza - Espanha }\end{array}$ & 1 & $7,14 \%$ \\
\hline Administração & UFRGS & 1 & $7,14 \%$ \\
\hline $\begin{array}{l}\text { Administração/Contabilidade } \\
\text { Gerencial }\end{array}$ & $\begin{array}{c}\text { University of Sheffield } \\
- \text { Inglaterra }\end{array}$ & 1 & $7,14 \%$ \\
\hline Educação & UFRN & 1 & $7,14 \%$ \\
\hline Ciências Sociais & UnB & 1 & $7,14 \%$ \\
\hline
\end{tabular}

Fonte: Elaboração própria, com base nos dados coletados.

\subsubsection{Perfil profissional}

No momento de ingresso no mestrado, a principal atividade remunerada dos mestres estava ligada ao mercado. De forma geral, cerca de $66,67 \%$ dos respondentes tinham sua principal atividade remunerada ligada ao mercado, enquanto os demais $29,17 \%$ tinham sua principal atividade remunerada ligada à academia. No núcleo Brasília, essa relação era ainda mais forte $(78,57 \%)$ do que no Nordeste $(57,41 \%)$.

Após a conclusão do mestrado, pode ser observada uma migração desses profissionais para a carreira acadêmica, tendo em vista que a relação entre a quantidade de mestres que tinham sua principal atividade remunerada ligada ao mercado ou à academia apresentou uma significativa aproximação. Do percentual de $66,67 \%$ anteriores, apenas $51,04 \%$ dos mestres mantiveram sua atividade remunerada principal ligada ao mercado $(44,80 \%$ tinham sua atividade remunerada principal ligada à academia e 4,16\%, a outras atividades). Entretanto, no núcleo Brasília, a situação continuou bastante próxima da observada no momento de ingresso no mestrado, com 76,19\% dos respondentes ligados principalmente ao mercado, fato que pode ser explicado devido ao grande número de funcionários públicos ligados aos 
órgãos federais localizados em Brasília. No entanto, no núcleo Nordeste, pode ser observada uma maciça migração para as atividades ligadas à academia, ao passo que o percentual de mestres ligados principalmente a estas atividades saltou de $38,89 \%$ no momento de ingresso para $64,82 \%$ no momento da realização da pesquisa, como se observa no Gráfico 3.

\section{Gráfico 3 - Principal atividade remunerada dos mestres em Ciências Contábeis, antes e após o mestrado.}

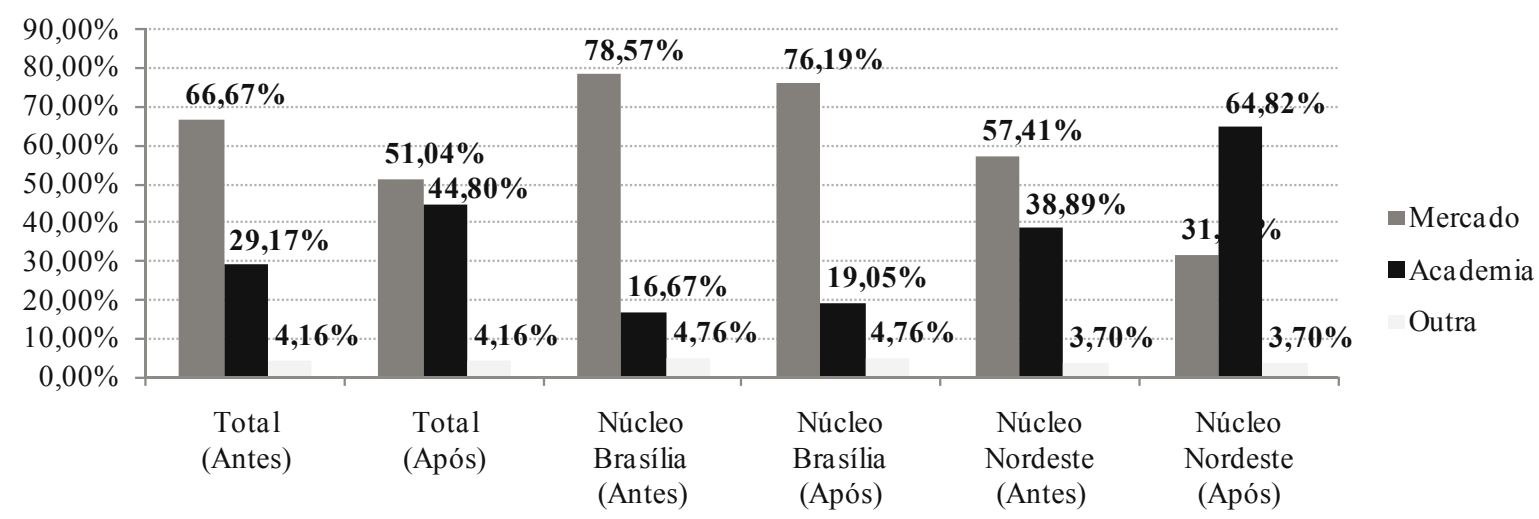

Fonte: Elaboração própria, com base nos dados coletados.

As variações e as migrações observadas no perfil profissional dos mestres levamnos a perceber que, no programa de pós-graduação analisado, o término do mestrado funciona como reorientador de opções profissionais. Essa gama de opções profissionais disponíveis aos mestres no Brasil é observada por Velloso (2004), ao notar que o trabalho dos mestres no Brasil se caracteriza por um amplo leque de atividades profissionais, das quais a docência é apenas uma delas e que não chega a ser majoritária em nenhuma das grandes áreas de atuação profissional estudadas pelo autor. Apesar de a grande maioria dos mestrados brasileiros ser regulamentada como mestrado acadêmico, estes estão formando, sobretudo, para ocupações fora da academia.

Em se tratando exclusivamente daqueles respondentes que lecionavam, nota-se que houve uma reorientação profissional de parte destes profissionais às atividades acadêmicas. Do total de respondentes (96), 60 eram docentes no ensino superior antes de ingressarem no mestrado, ou seja, 62,50\%. Após a conclusão do curso, este número se tornou mais expressivo, ao passo que 76 respondentes passam a lecionar no ensino superior, representando $79,17 \%$ dos mestres investigados. Isso ratifica a ideia de que o mestrado funciona como um reorientador de opções profissionais, tendo em vista que, embora sejam apenas $51,04 \%$ dos mestres que possuem a atividade principal ligada à academia, $79,17 \%$ dos respondentes atuam na academia em alguma IES, mesmo que seja como atividade secundária. 
A maioria dos mestres que atua na academia está ligada às IES privadas. Com a conclusão do mestrado, observa-se uma migração para as IES públicas, no entanto, as IES privadas ainda permanecem como principal destino após a conclusão do mestrado. Possivelmente, esta migração para as IES públicas se dá a partir da possibilidade de participação de concursos públicos para universidades públicas, o que é intensificado, também, pela carência desse tipo de profissional nas IES públicas dos estados nos quais está inserido o Programa.

Quanto ao tipo de IES na qual está inserido o mestre, antes do mestrado a maioria se concentrava nas faculdades $(46,67 \%)$, entretanto, após a conclusão do mestrado há uma migração para as universidades e centros universitários (48,86\% e 14,47\%, respectivamente). Notou-se, ainda, a participação de mestres em módulos de treinamento, em escolas federais da Receita Federal e da Polícia Federal e em escolas de negócios, classificados como outros $(2,64 \%)$, conforme Tabela 4.

\section{Tabela 4 - Características das IES onde lecionavam os mestres em Ciências Contábeis, antes e após o mestrado.}

\begin{tabular}{|l|c|c|c|c|}
\hline Total & \multicolumn{3}{|c|}{ Antes do mestrado } & \multicolumn{2}{c|}{ Após o mestrado } \\
\hline & N & $\%$ & N & $\%$ \\
\hline Natureza da IES & \multicolumn{5}{|l|}{} \\
\hline Pública & 23 & 38,33 & 35 & 46,05 \\
\hline Privada & 37 & 61,67 & 41 & 53,95 \\
\hline Tipo de IES & \multicolumn{5}{|l|}{} \\
\hline Universidade & 25 & 41,66 & 37 & 48,68 \\
\hline Centro Universitário & 7 & 11,67 & 11 & 14,47 \\
\hline Faculdade & 28 & 46,67 & 26 & 34,21 \\
\hline Outros & 0 & 0,00 & 2 & 2,64 \\
\hline Regime de trabalho & \multicolumn{5}{|l|}{} \\
\hline Dedicação exclusiva & 5 & 8,33 & 26 & 34,21 \\
\hline Tempo integral (T-40, T-40) & 16 & 26,67 & 17 & 22,37 \\
\hline Hora/aula & 30 & 50,00 & 29 & 38,16 \\
\hline Outros & 9 & 15,00 & 4 & 5,26 \\
\hline $\begin{array}{l}\text { Atividades envolvendo } \\
\text { pesquisa }\end{array}$ & \multicolumn{5}{|l|}{} \\
\hline Sim & 14 & 23,33 & 43 & 56,58 \\
\hline Não & 46 & 76,67 & 33 & 43,42 \\
\hline
\end{tabular}

Fonte: Elaboração própria, com base nos dados coletados.

Quanto ao regime de trabalho apresentado pelos mestres, observa-se que $50,00 \%$ dos respondentes trabalhavam pelo regime hora/aula no momento de ingresso no mestrado, enquanto $26,67 \%$ trabalhavam como tempo integral, $8,33 \%$ como dedicação exclusiva e 15,00\% como outros (módulos de treinamento, módulos de especializações e de escolas 
de negócios). Após a conclusão do mestrado, nota-se que o regime hora/aula ainda continua como o preponderante, muito embora tenha seu percentual de representatividade reduzido a $38,19 \%$. Já o regime de dedicação exclusiva apresenta um salto de aproximadamente 26 pontos percentuais, passando de $8,33 \%$ para $34,21 \%$.

Este último fato merece destaque tendo em vista que o tempo integral e a dedicação exclusiva foram estabelecidos pelo Decreto n. ${ }^{\circ}$ 64.096/69 (MOREL, 1979), fatores considerados como "essenciais para que um professor universitário ou pesquisador pudesse ser capaz de assegurar sua subsistência com um único emprego e assim concentrar-se na pesquisa" (FERNANDES, 1990, p. 67). Dessa forma, o aumento da quantidade de professores com dedicação exclusiva nas IES vem fortalecer a qualidade do ensino e da pesquisa nestas instituições.

Questionados quanto ao envolvimento em pesquisas em suas atividades, no momento de ingresso no mestrado, apenas $23,33 \%$ tinham suas atividades ligadas à pesquisa. Após a conclusão do mestrado, observa-se um envolvimento com pesquisa maior, saltando para 56,58\%. Como a qualificação para a docência no ensino superior e para a pesquisa constitui-se em uma das finalidades da pós-graduação stricto sensu, os resultados da pesquisa sugerem que esta finalidade vem sendo alcançada pelo Programa Multiinstitucional.

Investigando o regime atual de trabalho dos mestres em cada núcleo, nota-se que há significativas divergências de um para o outro. No núcleo Brasília, a maioria dos mestres que atua na academia possui vínculo com a IES por meio do regime hora/aula $(57,14 \%)$, enquanto no núcleo Nordeste a maioria deles é pelo regime de dedicação exclusiva $(41,67 \%)$, conforme o Gráfico 4. Esse fato pode ser explicado pela grande quantidade de mestres que atuam no mercado como funcionários públicos na cidade de Brasília, o que os leva a atuar na academia de forma secundária, pelo regime hora/aula nos centros universitários e nas faculdades da cidade.

\section{Gráfico 4 - Regime atual de trabalho dos mestres em Ciências Contábeis.}

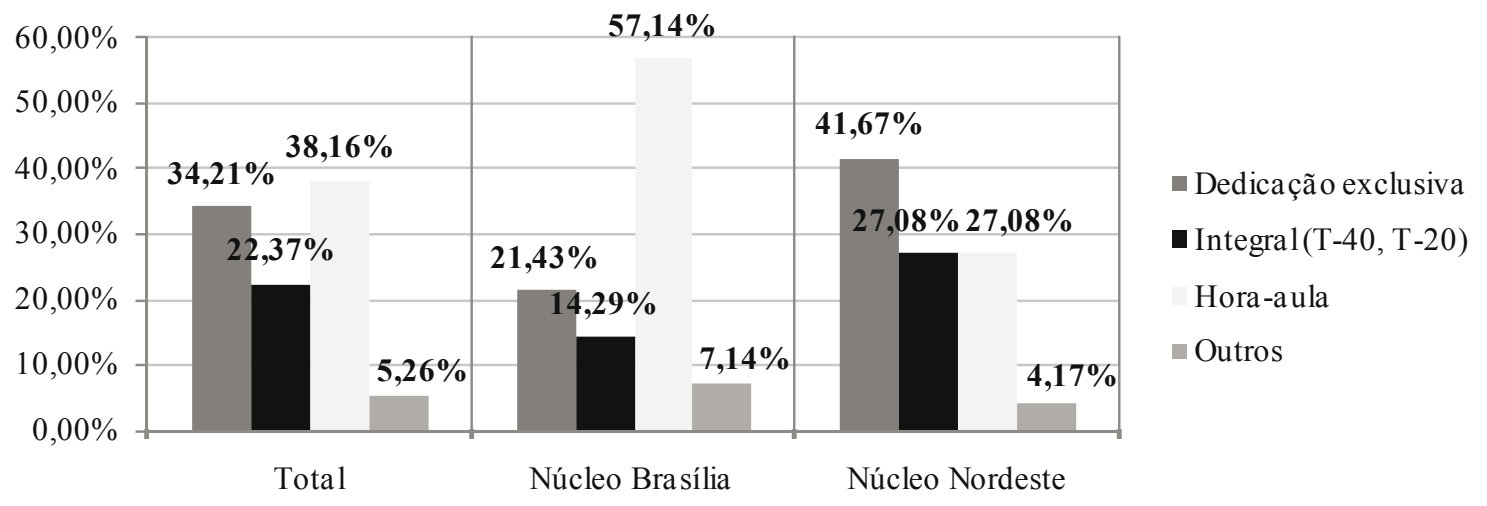

Fonte: Elaboração própria, com base nos dados coletados. 


\subsubsection{Remuneração dos mestres em Ciências Contábeis}

Ao investigar a remuneração média ${ }^{3}$ dos mestres em Ciências Contábeis titulados pelo Programa, podem ser observadas diferenças significativas entre as remunerações percebidas pelos egressos de cada núcleo, assim como na percebida por cada sexo.

A Tabela 5 demonstra que a remuneração média percebida pelos respondentes no momento de seu ingresso era de $\mathrm{R} \$ 3.968,31$ (76,04\% composta pelas atividades relacionadas ao mercado e $23,96 \%$ pelas atividades relacionadas à academia). Segundo Néri (2007), as remunerações apuradas para os profissionais de Ciências Contábeis àquele momento foram de $\mathrm{R} \$ 3.099,10$ para os graduados e de $\mathrm{R} \$ 7.085,24$ para os pós-graduados na área, portanto, inferior a obtida nesta pesquisa.

No núcleo Brasília, a remuneração média dos egressos é maior do que no núcleo Nordeste. Em Brasília, a remuneração média no momento de ingresso no mestrado era de $\mathrm{R} \$$ $5.213,17$, com maior representatividade da remuneração proveniente das atividades ligadas ao mercado (85,05\%). Isso é explicado pelo grande número de funcionários públicos existentes naquele núcleo, vinculados a órgãos públicos como o Senado Federal, a Câmara Federal, os Tribunais Superiores, a Polícia Federal, a Receita Federal, o Banco Central do Brasil e o Banco do Brasil. No núcleo Nordeste, esta média era de $\mathrm{R} \$ 3.000,10$, também com maior representatividade da remuneração ligada às atividades do mercado, no entanto, com uma representatividade sobre o total da remuneração menor do que no núcleo Brasília $(63,85 \%)$.

\section{Tabela 5 - Composição da remuneração média dos mestres em Ciências Contábeis, antes e após o mestrado.}

\begin{tabular}{|c|c|c|c|c|c|c|}
\hline \multirow{2}{*}{ Remuneração Média } & \multicolumn{2}{|c|}{ Total } & \multicolumn{2}{|c|}{ Núcleo Brasília } & \multicolumn{2}{|c|}{ Núcleo Nordeste } \\
\hline & $\mathrm{R} \$$ & $\%$ & $\mathrm{R} \$$ & $\%$ & $\mathrm{R} \$$ & $\%$ \\
\hline \multicolumn{7}{|l|}{$\begin{array}{l}\text { Remuneração antes } \\
\text { do mestrado }\end{array}$} \\
\hline Mercado & $3.017,33$ & 76,04 & $4.433,77$ & 85,05 & $1.915,67$ & 63,85 \\
\hline Academia & 950,98 & 23,96 & 779,40 & 14,95 & $1.084,43$ & 36,15 \\
\hline Total & $3.968,31$ & 100,00 & $5.213,17$ & 100,00 & $3.000,10$ & 100,00 \\
\hline \multicolumn{7}{|l|}{$\begin{array}{l}\text { Remuneração após o } \\
\text { mestrado }\end{array}$} \\
\hline Mercado & $5.049,41$ & 67,44 & $7.790,95$ & 80,05 & $2.917,09$ & 50,82 \\
\hline Academia & $2.437,56$ & 32,66 & $1.942,07$ & 19,95 & $2.822,94$ & 49,18 \\
\hline Total & $7.486,97$ & 100,00 & $9.733,02$ & 100,00 & $5.740,03$ & 100,00 \\
\hline
\end{tabular}

Fonte: Elaboração própria, com base nos dados coletados.

A remuneração média atual dos mestres em Ciências Contábeis é de $\mathrm{R} \$ 7.486,97$, ainda composta em sua maioria pela remuneração proveniente do mercado $(67,44 \%)$. Novamente, o núcleo Brasília apresentou uma remuneração média maior do que o núcleo 
Nordeste, $\mathrm{R} \$ 9.733,02$ a $\mathrm{R} \$ 5.740,03$. No entanto, pode ser observada uma redução da representatividade das atividades ligadas ao mercado no núcleo Nordeste, enquanto em Brasília ainda se percebe $80,05 \%$ da remuneração total proveniente do mercado. No Nordeste, observa-se um equilíbrio entre essas atividades, ao passo que são provenientes do mercado $50,82 \%$ da remuneração total e outros $49,18 \%$ são provenientes das atividades ligadas à academia (como observado na Tabela 6).

Quando se realiza o teste de significância para diferença entre duas médias empareIhadas ( $\mathrm{t}$ de Student), com um nível de significância de $5 \%$, observa-se que a diferença entre as médias de remuneração atual do mercado e da academia é significativa $\left(t_{\text {cal }} 3,93>t_{\text {tab }}\right.$ 1,96). Isso demonstra que, em relação aos mestres do programa analisado, a remuneração do mercado é superior à remuneração da academia. Essa afirmação pode ser estendida para o núcleo Brasília, tendo em vista que a diferença entre as médias do mercado e da academia é ainda maior ( $\left.t_{\text {cal }} 5,68>t_{\text {tab }} 1,96\right)$, no entanto, não se pode afirmar o mesmo quanto à remuneração dos egressos do núcleo Nordeste, tendo em vista não haver significância estatística na diferença entre as médias de remuneração do mercado e da academia $\left(t_{\text {cal }} 0,13<t_{\text {tab }} 1,96\right)$.

A menor ${ }^{4}$ remuneração atual observada entre os mestres foi $R \$ 1.600,00$, pertencente a um mestre titulado pelo núcleo Nordeste, que possui sua única atividade remunerada ligada à academia e, a maior remuneração, $R \$ 24.900,00$, pertencente a um mestre que possui sua principal atividade remunerada ligada ao mercado e a secundária ligada à academia (núcleo Brasília). O desvio padrão da média de remuneração total atual é $\mathrm{R} \$$ $5.006,66$, o que demonstra grandes divergências entre a remuneração total dos mestres.

Considerando-se a progressão salarial apresentada entre os períodos de ingresso e conclusão do mestrado, percebe-se que, em média, houve um aumento médio de $47,00 \%$. No entanto, não se pode afirmar que esse aumento foi exato, tendo em vista a inflação ocorrida no período (entre os anos de 2000 e 2007) e a diversidade de períodos de ingresso apresentada pelos mestres (primeiro ingresso em janeiro de 2000 e último em julho de 2005). Mesmo assim, confrontando-se o aumento apresentado e a inflação ocorrida nesse período, pode-se afirmar que houve aumento. Quanto à influência do título de mestre nesse aumento, não se pode estabelecer que ele tenha sido ocasionado única e exclusivamente pelo título. Entretanto, baseado em autores como Velloso (2002), Machado (2003), Martins et al. (2007) e Cunha (2007), atribui-se parcela desse aumento à obtenção do título de mestre em Ciências Contábeis, principalmente, na remuneração proveniente das atividades ligadas à academia.

Quanto à remuneração média atual dos mestres em Ciências Contábeis, segundo o gênero, em média, os homens possuem remuneração maior do que a das mulheres. De forma geral, os homens possuem uma remuneração média de $R \$ 8.780,57$, enquanto as mulheres recebem $\mathrm{R} \$ 5.017,33$. Dessa forma, o teste de significância para diferença entre duas médias revelou que a diferença entre homens e mulheres é significativa estatisticamente $\left(\mathrm{t}_{\mathrm{ca}} \mid 4,54>\mathrm{t}_{\text {tab }} 1,96\right)$. 
No núcleo Brasília, essa diferença é ainda mais expressiva, ao passo que os homens recebem, em média, $\mathrm{R} \$ 11.368,69$ e as mulheres recebem $\mathrm{R} \$ 6.084,23$ (quase a metade dos homens), também demonstrando uma diferença entre médias significativa estatisticamente $\left(\mathrm{t}_{\text {cal }} 4,30>\mathrm{t}_{\text {tab }}\right.$ 1,96). No núcleo Nordeste, esta diferença é menor, mas ainda presente. Enquanto os homens recebem uma remuneração média de $\mathrm{R} \$ 6.573,05$, as mulheres recebem $R \$ 4.323,90$, com diferença entre as médias também significativa $\left(t_{\text {cal }} 2,04>t_{\text {tab }}\right.$ 1,96), como pode ser observado no Gráfico 5.

\section{Gráfico 5 - Remuneração média atual dos mestres em Ciências Contábeis, segundo o gênero.}

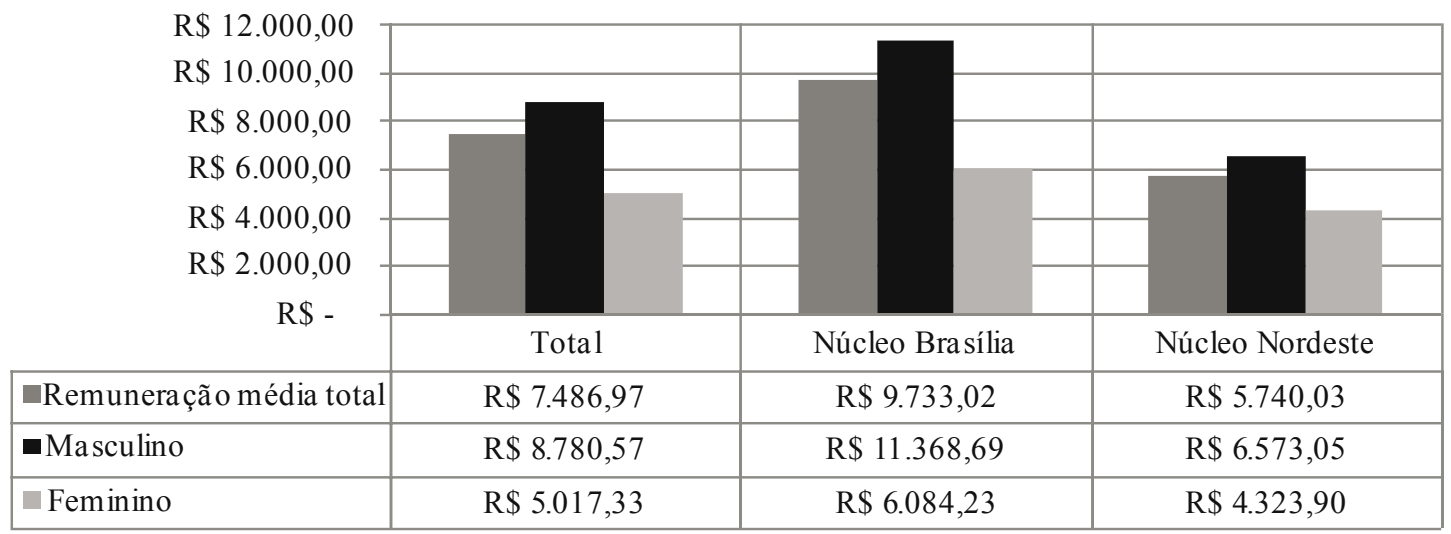

Fonte: Elaboração própria, com base nos dados coletados.

Tais diferenças de médias coadunam com a ideia de que ainda exista discriminação de sexo no mercado de trabalho brasileiro, como observado por Martins et al. (2007) em um estudo realizado com contadores dos Estados da Paraíba e do Rio Grande do Norte, estados estes integrantes do Programa Multi-institucional.

\section{CONSIDERAÇÕES FINAIS E LIMITAÇÕES DO ESTUDO}

Este estudo fundamentou-se na Teoria do Capital Humano para investigar a influência do título de mestre em Ciências Contábeis no perfil do egresso do Programa Multiinstitucional da UnB/UFPB/UFPE/UFRN, No tocante a isto, quatro importantes conclusões podem ser enumeradas:

1. Em se tratando do perfil do egresso no Programa, verificou-se que, em sua maioria, são homens (65,63\%), atualmente moram em um desses estados/cidade $(80,21 \%)$, possuem em média 39 anos e são casados (64,58\%). Quanto às suas trajetórias acadêmicas, terminaram a graduação em média aos 25,63 anos; a maioria é graduada em Ciências Contábeis (93,75\%); 77,08\% possuem ao menos uma especialização; e apenas 1,04\% possui doutorado (enquanto outros $13,54 \%$ ainda o estão cursando). 
2. O tempo transcorrido entre o término da graduação e o início do mestrado foi de aproximadamente 7 anos e 2 meses, observando-se uma diferença significativa entre os dois núcleos, ao passo que em Brasília esse período ultrapassou os 8 anos, enquanto no Nordeste ele foi de 6 anos.

3. Quanto às atividades profissionais, observou-se que, antes do mestrado, $66,67 \%$ dos mestres possuía sua atividade remunerada principal ligada ao mercado. Após o mestrado, esse percentual caiu para 51,04\% (44,80\% deles passaram a ter sua principal atividade remunerada ligada à academia), demonstrando haver uma migração natural dos mestres para a área acadêmica. Considerando-se todos aqueles que lecionam, observa-se, que antes do mestrado, $62,50 \%$ dos mestres ministravam aulas em alguma IES, entretanto, após a conclusão do mestrado, este número sobe para $79,17 \%$. Isto evidencia a influência do título de mestre na reorientação profissional dos egressos do Programa, ao passo que parcela significativa desses profissionais passa a atuar na área acadêmica.

4. Após o mestrado, em sua maioria, estes profissionais ministram aulas em alguma IES privadas $(53,95 \%)$, em regime de hora/aula $(38,16 \%)$ e afirmam estarem envolvidos em pesquisas nessas instituições (56,58\%). A remuneração média observada foi de $\mathrm{R} \$$ 7.486,97, sendo $\mathrm{R} \$ 5.049,41$ provenientes do mercado e $\mathrm{R} \$ 2.437,56$ da academia. Estes fatores ratificam os preceitos da Teoria do Capital Humano, uma vez que pode ser observada a influência positiva da referida escolaridade na empregabilidade do egresso do Programa e, em sua renda, a qual apresentou um sensível crescimento após a obtenção do título.

A pesquisa ora realizada foi restrita aos mestres de um determinado programa de pós-graduação, em um determinado período de tempo. Devido a isso, os resultados aqui obtidos representam um recorte da realidade em questão, não possuindo a intenção de serem colocados como respostas definitivas ao problema investigado. Sugere-se que sejam realizados novos estudos a partir deste, a fim de constatar novas tendências.

\section{REFERÊNCIAS}

BARROS, R. P.; MENDONÇA, R.; HENRIQUES, R. Pelo fim das décadas perdidas: educação e desenvolvimento sustentável no Brasil. Rio de Janeiro: IPEA, 2002.

BECKER, G. S. Investment in human capital: a theoretical analysis. The Journal of Political Economy, Chicago, v. 70, n. 5, p. 9-49, oct. 1962.

BEUREN, I. M. (org.). Como elaborar trabalhos monográficos em contabilidade: teoria e prática. 3. ed. São Paulo: Atlas, 2006.

BLAUG, M. La metodologia de la economia. Trad. Ana Martinez Pujana. Madrid: Alianza Editorial, 1985. 
BLAUG, M. The empirical status of human capital theory: a slighthy jaundiced survey. Journal of Economic Literature, Nashville, v. 14, n. 3, p. 827-855, sep. 1976.

BLAUG, M. The rate of return on investment in education in Great Breat. The Manchester School, Manchester, v. 33, n. 3, p. 205-251, 1965.

BROWN, D. S.; HUNTER, W. Democracy and human capital formation: education spending in Latin America, 1980 to 1997. Comparative Political Studies, v. 37, n. 7, p. 842-864, sep. 2004.

CUNHA, J. V. A. Doutores em ciências contábeis da FEA-USP: análise sob a óptica da teoria do capital humano. 2007. 261f. Tese (Doutorado em Contabilidade e Controladoria) Faculdade de Economia, Administração e Contabilidade, Universidade de São Paulo, São Paulo, 2007.

CURI, A. Z. A relação entre o desempenho escolar e os salários no Brasil. 2006. 79f. Dissertação (Mestrado em Economia) - Faculdade de Economia, Administração e Contabilidade, Universidade de São Paulo, 2006.

FERNANDES, A. M. A Construção da ciência no Brasil e a SBPC. Brasília: UnB, 1990.

FERREIRA, P. L. L. Impactos do capital humano no crescimento econômico do Brasil, entre 1977 e 2005. 2008. 93f. Dissertação (Mestrado em Economia) - Faculdade de Ciências Econômicas, Universidade do Estado do Rio de Janeiro, Rio de Janeiro, 2008.

FRIGOTTO, G. Educação e crise do capitalismo real. 5.ed. São Paulo: Cortez, 2003.

GASTALDON, C. F. Escolha da profissão no ensino superior: a relação entre educação e a teoria do capital humano nesse processo - estudo de caso na cidade de Criciúma/Santa Catarina. 2007, 148f. Dissertação (Mestrado em Educação) - Programa de Pós-Graduação em Educação, Universidade do Extremo Sul Catarinense, Criciúma, 2007.

GIL, A. C. Métodos e técnicas de pesquisa social. 5. ed. São Paulo: Atlas, 1999.

HUNTER, W.; BROWN, D. S. World bank directives, domestic interests, and the politics of human capital investment in Latin America. Comparative Political Studies, v. 33, n. 1, p. 113-143, feb. 2000.

LIMA, R. Mercado de trabalho: o capital humano e a teoria da segmentação. Pesquisa e Planejamento Econômico, Rio de Janeiro, v. 10, n. 1, p. 217-272, abr. 1980. 
LOENING, J. L. Effects of primary, secondary and tertiary education on economic growth. World Bank Policy Research Working Paper, n. 3610, mai. 2005.

MARTINS, O. S.; VASCONCELOS, A. F.; BRASIL, A. M. S.; MONTE, P. A.; LEITE FILHO, P. A. M. Fatores que influenciam os salários dos contadores à luz das teorias econômicas do emprego: um estudo exploratório na Paraíba e no Rio Grande do Norte. In: Simpósio de Excelência em Gestão e Tecnologia (SEGeT), 4., Rezende/RJ. Anais... Rezende: 2007.

MINCER, J. Schooling, experience, and earnings. New York: Columbia University Press, 1974.

MORETTO, C. F. Ensino superior, escolha e racionalidade: os processos de decisão dos universitários do município de São Paulo. 2002. 201f. Tese (Doutorado em Economia) Faculdade de Economia, Administração e Contabilidade, Universidade de São Paulo, São Paulo, 2002.

MOREL, R. L. M. Ciência e Estado: a política científica no Brasil. São Paulo: T. A. Queiroz, 1979.

NERI, M. (coord.). O retorno da educação no mercado de trabalho. Disponível em: <http:// www.fgv.br/cps>. Acesso em: 30 dez. 2007.

PSACHARAPOULOS, G.; PATRINOS, H. A. Returns to investment in education: a further update. World Bank Policy Research Working Paper, n. 2881, set. 2002.

RICHARDSON, R. J. Pesquisa social: métodos e técnicas. 3. ed. rev. amp. São Paulo: Atlas, 2008.

RIDDELL, W. C. The social benefits of education: new evidence on an old question. In: Taking Public Universities Seriously (conference), University of Toronto, 2004. Disponível em: <http://www.utoronto.ca/president/04conference/downloads/Riddell.pdf>. Acesso em: 19 jan. 2009.

ROBEYNS, I. Three models of education: rights, capabilities and human capital. Theory and Research in Education, v. 4, n. 1, p. 69-84, 2006.

ROSS, S. A.; WESTERFIELD, R. W.; JAFFE, J. F. Administração financeira. São Paulo: Atlas, 1995.

SCHULTZ, T. W. Investment in human capital. The American Economic Review, Cambridge, v. 51 , n. 1 , p. 1-17, mar. 1961. 
SCHULTZ, T. W. O capital humano: investimento em educação e pesquisa. Trad. Marcos Aurélio de Moura Matos. Rio de Janeiro: Zahar Editores, 1973.

SHEEHAN, J. A economia da educação. Trad. Fernando Castro Ferro. Rio de Janeiro: Zahar Editores, 1975.

SILVA, A. C. R. Metodologia da pesquisa aplicada à contabilidade: orientações de estudos, projetos, artigos, relatório, monografias, dissertações, teses. São Paulo: Atlas, 2003.

SOARES, A. A. R. As mudanças na educação brasileira no contexto neoliberal e suas implicações no ensino superior. In: Congresso Latinoamericano de Humanidades, 8., 2007, Campos de Goytacazes/RJ. Anais... Campos de Goytacazes: 2007.

STURMAN, M. C.; WALSH, K.; CHERAMIE, R. A. The value of human capital specificity versus transferability. Journal of Management, v. 34, n. 2, p. 290-316, apr. 2008.

VELLOSO, J. A pós-graduação no Brasil: formação e trabalho de mestres e doutores no país. Brasília: Capes, 2002.

VELLOSO, J. Mestres e doutores no país: destinos profissionais e políticas de pós-graduação. Caderno de pesquisas, Brasília, v. 34, n. 123, p. 583-611, set./dez. 2004.

ZULA, K. J. CHERMACK, T. J. Human capital planning: a review of literature and implications for human resource development. Human Resource Development Review, v. 6, n. 3, p. 245-262, sep. 2007.

Artigo originalmente apresentado no IAAER-ANPCONT ( ${ }^{\text {rd }}$ ), São Paulo/SP, 10 a 12 de junho de 2009.

Na realização do cálculo da média de idade do término da graduação foi utilizada a mesma metodologia utilizada por Velloso (2002) e Cunha (2007), ou seja, a partir do cálculo por subtração dos intervalos entre os anos de nascimento e início e término de sua formação acadêmica, permitindo, assim, a realização de comparações.

Para cálculo da remuneração média recebida pelos mestres em Ciências Contábeis foi solicitado a cada mestre que informasse o valor exato da remuneração recebida à época em Reais ou em salários mínimos, de cada uma de suas atividades remuneradas. Posteriormente, as informações em salários mínimos foram transformadas em valores de Reais a partir do valor do salário mínimo vigente no momento do ingresso de cada mestre. Dessa forma, pode-se calcular o valor médio exato recebido pelos mestres no momento de seu ingresso, tendo em vista, também, que todas as remunerações foram recebidas em Reais. deste, com remuneração igual a zero, a qual foi desconsidera durante o cálculo das médias salariais. 